\title{
A Conceptual Framework for Investigating Organizational Control and Resistance in Crowd-Based Platforms
}

\author{
David A. Askay \\ California Polytechnic State University \\ daskay@calpoly.edu
}

\begin{abstract}
This paper presents a research agenda for crowd behavior research by drawing from the organizational control literature. It addresses the need for research into the organizational and social structures that guide user behavior and contributions in crowd-based platforms. Crowd behavior is situated within a conceptual framework of organizational control. This framework helps scholars more fully articulate the full range of control mechanisms operating in crowd-based platforms, contextualizes these mechanisms into the context of crowd-based platforms, challenges existing rational assumptions about incentive systems, and clarifies theoretical constructs of organizational control to foster stronger integration between information systems research and organizational and management science.
\end{abstract}

\section{Introduction}

Organizations are increasingly interested in harnessing the collective actions of crowds to meet business goals [1]. This has resulted in the proliferation of crowd-based platforms supporting collective intelligence and crowdsourcing efforts that coordinate the contribution of user-generated content-product reviews, encyclopedia articles, and current traffic conditions. Consequently, the crowd has become a powerful source of knowledge that guides not only the decisions of the public, but also decisions made by organizations [2]. As organizations like Amazon, Waze, and Wikipedia turn to the crowd to produce the content that their business models depend on, the challenge of how to motivate and govern the crowd has become the topic of much research [1,3]. While there is scholarly interest in the "actions and policies employed to effectively manage the crowd and steer them” [4], there remains limited research about effective mechanisms for governing the crowd [5].
Crowd-based platforms coordinate action through decomposing tasks and encouraging individuals to participate by providing intrinsic (e.g., fun, enjoyment) and/or extrinsic (e.g., status, money, social interaction, etc.) motivators [3]. Three recent Information Systems (IS) reviews of crowdsourcing research [6, 4, 7] emphasize the importance of designing effective incentive systems. However, research on motivation is somewhat disparate, with various categorizations and often inconsistent findings as to which incentives are the most effective [4]. Moreover, this approach can be limited by its often deterministic and rational assumptions of user behavior and motivation, which overlooks normative and social aspects of human behavior [8]. To more fully understand the dynamics of crowd behavior and governance of crowd-based projects, IS researchers need a sophisticated way to conceptualize the complex social and organizational processes that guide the behavior and actions of the crowd.

To fill this conceptual gap in the crowd behavior literature, this paper draws from organizational control research. Organizational control refers to the strategies used by managers to align worker behaviors to organizational objectives $[9,10]$. While IS scholars have occasionally focused on organizational control mechanisms [11, 12, 13], an explicit consideration of control mechanisms is particularly limited in the crowdsourcing and collective intelligence literature.

This paper makes four contributions to the literature. First, I present a framework that more fully articulates the range of control mechanisms that guide the behavior of the crowd. Second, I contextualize this framework through providing examples of organizational control research in crowd-based platforms. Third, I identify promising new directions for crowd behavior research by bringing in the ontologically and methodologically diverse organizational control literature [14]. Fourth, this paper clarifies theoretical constructs of organizational control in order to foster integrative 
research drawing from both IS and organizational science literature.

\section{Organizational Control and Crowds}

This section defines organizational control, summarizes an input-process-output model of organizational control, and describes resistance to organizational control.

\subsection{What is Organizational Control?}

While IS researchers often note the 'loss of control' associated with crowdsourcing [5], control is a fundamental aspect of all organizations and is needed to coordinate goal-oriented behaviors [15]. As will be described below, crowd-based platforms use a diverse range of control mechanisms. Organizational control includes the mechanisms used by managers to direct, motivate, and encourage worker behaviors to align with organizational objectives [9, 10]. The need for organizational control stems from the competing interests that exist between individuals and organizations, which can be resolved though control mechanisms (e.g., rules, rewards, punishments, supervision, etc.) that subordinate the individual's goals to those of the organization. Control strategies include the incentives that motivate some behaviors (e.g., incentive systems) and also the mechanisms that constrain other behaviors.

Various control mechanisms are used by organizations, including policies [16], bureaucratic rules [17], culture [18], incentive systems and supervision [19], identity [20], and technological design [9]. Scholars have offered several approaches to categorizing these control strategies [9, 10, 21, 22], though most distinguish between formal and informal control strategies [22, 11].

Formal control strategies (also called rational control) seek to influence behavior through the explicit and codified structuring of inputs, tasks, processes, behaviors, and/or outcomes - in essence providing incentives in return for completing welldesigned tasks within certain parameters or punishing those that deviate from this organizationally designed process. This forms the basis for the incentives systems currently used by many crowd-based platforms. Additionally, behavior can be directed through bureaucratic rules, direct supervision, and technological design. These control strategies are premised on the assumptions that individuals are primarily rational and view work as an economic exchange, and that there is a generally linear cause- and-effect relationship between incentives and action [22].

By contrast, informal control strategies (also called normative or social control) seek to guide behaviors through fostering collective norms, identity, culture, and values in members. A theoretically and ontologically diverse range of scholars have considered these kinds of informal control strategies [23, 21, 20, 9, 24, 14, 25]. In general, socio-ideological control occurs when individuals are socialized into an organization's system of beliefs, values, and norms (i.e., corporate culture), which provides a particular organizational reality that acts as a sense-making device for member behaviors. When these values and norms are internalized, members can monitor their own behaviors to ensure that they align with organizational goals. Informal control mechanisms are particularly useful for knowledge work, where required creativity, ambiguity, and flexibility are not conducive to bureaucratic control strategies that dictate a rule for every contingency [26]. Still, control strategies often do not fit firmly in one of these two categories, and a single mechanism may possess attributes of both formal and informal strategies [10, 21].

\subsection{Framework of Organizational Control}

A recent synthesis of organizational control research uses an input, process, output (IPO) model to produce a useful model for conceptualizing the various mechanisms in a control system [10]. This framework classifies control systems on the degree to which formal and informal control mechanisms target the input, behavior, and output of the system. It presents a control system as comprised of several control mechanisms (e.g., bureaucratic, technological, direct, socio-ideological, etc.) that each have a control target (e.g., input, behavior, output) in the organization. Input targets include mechanisms that control how inputs (e.g., who is allowed to participate) to the system are qualified, chosen, and prepared, such as through the selection, training, and socialization of individuals. Behavior targets focus on controlling the manner in which individuals perform actions or complete tasks. Finally, output targets include mechanisms that control qualitative and quantitative outcomes, such as profits, quality standards, production volume, and speed. This framework draws attention to the various control mechanisms that collectively comprise a control system.

Most IS research on crowd behavior has focused on the study of formal control mechanisms (i.e., 
incentive systems) that target the outputs produced by the crowd [4]. By contrast, little scholarly attention has been directed towards control mechanisms that target inputs (e.g., who is included and excluded from participating, socialization and training, etc.) and behaviors (e.g., how and when contributions are produced). Additionally, informal control mechanisms have been understudied in the context of crowd behavior, if mentioned at all. Finally, little research has addressed how several control strategies may work in tandem to control crowd behavior, an approach that is advocated for by organizational scholars [21, 26, 27].

\subsection{Resistance to Organizational Control}

Control is often implicitly considered a straightforward - even deterministic_process by scholars, whereby the application of proper control mechanisms produce desired user behavior. This is reflected in IS studies suggesting that "task designers must guess at the right combination of incentives and iterate until success" [3] or simply identify the "right incentive mechanism” [4] for encouraging participation. However, other scholars challenge this rational deterministic view of control by questioning the assumption that "control is achieved by designing and applying appropriate structures, procedures, measures and targets; and, relatedly, that resistance to these mechanisms is symptomatic of ‘poor design’ or 'poor management' that can be rectified by restructuring” [20].

Critical approaches to organizational control, by contrast, view organizations as socially constructed and as sites of power and resistance [14], where divergent interests among stakeholders often provokes subversion, protest, sabotage, and other deviant behaviors [28, 29, 30, 31, 32]. Indeed, conflict and struggle may be as commonplace in crowds as compliance and consent. Yet resistance as core aspect of organizational life is overlooked in crowd behavior research, where participation is often conceived of as binary-individuals participate or they do not. By focusing scholarly attention to the struggles experienced by various stakeholders, we can better understand the full range of stakeholder experiences in these platforms and design more humane and democratic platforms.

A recent example underscores the less visible actions of control and resistance that occur in crowdbased platforms. Waze is a GPS-based navigation application for smartphones that incorporates realtime user-reported accidents, traffic, and police cars to optimize routes. When a detour consistently rerouted traffic through a previously quiet neighborhood, local residents began posting false reports during rush hour in effort to redirect traffic away [33]. However, these acts of resistance were suppressed through two organizational control mechanisms. First, other Waze users were able to invalidate the false reports through submitting their own report. Second, an algorithm used data transmitted by the smartphone (e.g., speed, direction, etc.) to suspend the user accounts of those suspected of submitting false reports. Together, these control mechanisms were sufficient to overcome the resistance efforts of these stakeholders and marginalize their interests. Given the scale at which crowd-based platforms operate, the question of how control systems produce winners and losers as stakeholders struggle over divergent goals becomes an important area of study.

\section{Organizational Control Mechanisms}

A summary of formal and informal control mechanisms is presented. Examples of crowd-based platforms are provided, drawing from studies that explicitly or implicitly embody these control mechanisms. This reveals a variety of yet unconsidered control mechanisms currently used in crowd-based platforms.

\subsection{Bureaucratic Control}

Bureaucratic control relies on impersonal and formal system of rules, procedures, and roles to guide worker behavior [17], although some rules may also be informal. Such systems can, for example, dictate the kinds of people selected for a task, the manner by which tasks are supposed to be completed, the kinds of behaviors that are acceptable, and how performance is evaluated, rewarded, and punished. Often organizational control is achieved by explicitly linking worker behaviors to sanctions or rewards, targeting extrinsic and intrinsic motivators of these individuals [34]. Extrinsic motivation induces cooperation through the promise of instrumental benefits, such as money, status, or reputation. Conversely, intrinsic motivation results from individuals cooperating due to the task being personally rewarding, such as enjoyment, fun, and altruism.

The use of bureaucratic control is identifiable in many crowd-based platforms, as rule-based contributions are used to coordinate the collective action of unconnected individuals. Other rules may motivate participation by providing clear guidelines or criteria for achieving certain symbols of status 
(e.g., badges or titles) or earning rewards (e.g., money). Alternatively, individuals may participate more when they know that their contributions are quantified and made visible on their profile. A recent literature review concluded that studies of incentive systems and motivation are among the most studied aspects of crowd behavior in the IS literature [4]. Yet, these findings are often inconsistent, with it remaining unclear which, if any, of these intrinsic and extrinsic incentives are the most important for recruiting and fostering participation.

Two important observations about crowd behavior research arise from these findings. First, extant IS research focuses heavily on incentives that target outputs where participants are rewarded for their contributions with status, recognition, badges, or money. Less often examined are formal rules that target inputs (e.g., who gets to participate) or behaviors (e.g., how people perform tasks) in the system. Second, most research examines rules that motivate certain actions, while overlooking formal rules act to constrain other actions. As organizations seek to adequately govern and control the crowd, more research is needed to understand the extent to which formal rules reward and punish, not just outputs, but also inputs and behaviors.

3.1.1. Example of Bureaucratic Control. A study of reviewers on Yelp reveals how bureaucratic rules, in the form of the terms of service, impacts crowd behavior. While Yelp promotes empowerment and transparency through its online review system, the terms of service disallow users from including civic or political discourses in their reviews [35]. Kuehn describes how some participants on Yelp "monitored and flagged political reviews that did not fit Yelp’s terms of service” [36], which limited the discursive agency available to users in their evaluations on Yelp. This bureaucratic rule, enforced through self-policing, suppressed and filtered reviews deemed inappropriate by Yelp. These rules construct Yelp as "not the place"' for consumer politics despite promoting itself as a platform for empowerment and transparency. More importantly, users are empowered to produce only the type of content that aligns the objectives of the greater organization-the crowd is not simply encouraged to contribute, but to contribute the 'right' kind of content.

This study reveals an important, yet understudied, way in which formal rules are used to constrain the kind of content that is produced in a crowd-based platform. Perhaps most interesting is that some users chose to self-police the reviews to ensure that these rules were being followed by others. This reveals that not only did these members know about these rules, but that they were also sufficiently internalized to the point that they would self-police content despite no clear incentive. A deeply unsatisfying explanation of this behavior is that some members just happen to take on extra tasks for no apparent reason. These members are likely driven by commitment to the organization and its goals through socio-ideological control (described below) or perhaps the kind of concertive control found in self-managed teams [24]. Here, the alignment of two different control mechanisms work together to produce a control system that discourages and eliminates certain kinds of contributions to Yelp. However, this may also be a cautionary lesson as organizational research reveals that rules deemed 'bad' by members can also become dysfunctional [37, 38, 39], leading individuals to resist, engage in mischief, or leave the organization. In other words, some formal rules may act as a disincentive for participation.

\subsection{Technological Control}

Technological control is exercised through organizational technologies that substitute for the presence of direct supervision and constrains the amount of discretion available to workers [40]. For example, assembly lines can control the pace of work in factories, while soda fountains at McDonald's dispense precisely the right amount of soda into cups to eliminate waste [30]. Such mechanisms severely limit the ability of workers to deviate from the organizationally planned process, highlighting their use in targeting the behavior of participantsconstraining how and when they work. Other technologies can provide the constant threat of surveillance, acting as an invisible supervisor that can notify managers or take action when a worker deviates from a task.

There are several ways in which technological control can be exerted in crowd-based platforms. Contractors on the digital labor market Upwork, for example, can be surveilled by their employers through recording their desktop screens while they work. More recently, the use of algorithms has also explored as a means of control [41, 42]. For example, the Yelp filter automatically removes roughly $20 \%$ of reviews submitted to the website that are suspicious [43]. While this is done to remove fake or paid-for reviews, it also may upset individuals that provided honest opinions only to find them removed for an unknown reason.

Technological control can also be linked to the concept of affordances, which has been increasingly used in the IS field [44, 45]. Affordances of a technological artifact are the potentials for action 
perceived by an individual [45], which can be mediated by group norms [46]. As a result, affordances of technology are not viewed deterministic, but rather accept that technologies can be adopted in unintended ways by users. This has been applied to crowdsourcing by IS researchers who recognize that "design elements of a variety of architectures that constrain and afford purposeful human actions" [47]. In this sense, the affordances designed into crowdsourcing platforms might act to shape crowd behavior. Still, while affordances are often conceived of as enabling and constraining action, the explicit study of affordances (or lack thereof) being strategically designed (or omitted) from crowd platforms to further organizational goals emerges as understudied.

3.2.1. Example of Technological Control. One study investigating a peer feedback system on a popular hospitality exchange website provides insights to how technological control through affordances may function in crowd-based platforms [48]. This study found that the contribution of negative feedback was inhibited by the affordances of the system. Specifically, users of this website reported that their negative experiences could not be adequately explained within the 1,000 character limit available for references and that the required labeling of feedback as negative, neutral, or positive did not align with their subjective experience. As a result, many users did not feel empowered to contribute their negative experiences. This contributed to the overall positive bias of feedback on the system and may have (intentionally or unintentionally) benefited the organization because new members (and hence income) were recruited through its advertised high level of positive feedback. Interestingly, though, these users resisted this technological control by instead expressing negative experiences in the discussion forums - a channel with different technological affordances that did not restrict the length of comments nor require labels. This shows that users were willing to contribute the content of their negative experiences, but that the technological affordances of this platform restricted the kinds of feedback that users were able to produce.

\subsection{Direct Control}

Direct control is generally enacted through a formalized hierarchical supervisor-subordinate relationship in which the supervisor has the legitimate authority to instruct workers on what to do, monitor their behavior, and reward and punish them as needed. This definition suggests that it is unlikely that direct supervision exists in crowdsourcing. Indeed, scholars assert that crowdsourcing "implies voluntary participation of individuals, with no hierarchy or contract related constraint ... [c]oordination by hierarchy does not take place” [49]. Other conceptualizations of crowdsourcing and collective intelligence emphasize that lack of hierarchy is a condition of crowdsourcing [1] and that crowds lack direct supervision [3].

3.3.1. Example of Direct Control. Emerging research, however, challenges the assumed lack of direct supervision of the crowd. Several studies have identified people holding the position of a community manager operating in crowd-based platforms. In one study, the community manager was found to play an integral role in managing the production of usergenerated content. As Kerr and Kelleher explain, "[w]hen share value depends on market share, unique users, and clicks, companies are turning to a range of techniques to "engage," retain, and convert user activity into revenue [including] the employment of community managers" [50]. These community managers were found to organize offline events, manage problematic user behaviors, and deal with the emotions of users. Other scholars found that community managers monitor and control crowd activity and "promote the participation and collaboration of stakeholders in order to improve some 'crowdsourcing' processes” [51]. Still, relatively little is known about these community managers and the extent to which they are effective. They reveal, however, that as harnessing crowds has become more central to organizations, more formal and rational forms of direct control appear to be implemented to guide crowd behaviors. It also illustrates the importance considering how unexpected forms of control may operate in crowdbased platforms.

\subsection{Socio-Ideological Control}

While previous control mechanisms are founded on a rational approach to human behavior, socioideological control mechanisms stem from a normative approach to control, in which the organization can foster the development of beliefs and values that workers are expected to internalize and use as a guide for their behaviors [21]. Scholars have noted a lack of conceptual consensus of informal approaches [10], contributing to development of several overlapping theories of socioideological control, including corporate culture, 
cultural control [52, 53], clan mechanisms [9], disciplinary control [54, 55], and identity-based control [20, 23]. These theories are likewise differentiated by their intellectual traditions and ontological and epistemological orientations, including structural functionalism, post-structuralism, social constructivist, post-modernism, critical theory, positivism, and interpretism.

Informal control mechanisms generally involve "a process of reality construction that allows people to see and understand particular events, actions, objects, utterances, or situations in distinctive ways" [56]. Through discourse that shapes the organizational reality of members, organizations can influence behavior by guiding worker values, beliefs, norms, taken-for-granted assumptions, concepts of right and wrong, and good and bad. Ultimately, this serves to eliminate or minimize the incongruence that exists between individual and organizational goals.

Socio-ideological control mechanisms are less obtrusive than rational control systems as they do not rely on external structures of the organizations (supervisors, technology, or rules). Rather, through a strong culture or identity fostered through organizational discourses, workers are encouraged to monitor their own behavior to ensure that they make decisions and actions that align with organizational goals. This places emphasis on understanding how language and organizational discourse (e.g., written documents, speech, pictures, symbols, etc.) is drawn upon by members to constitute their social reality and organizational life [57]. Discourse can be thought of as "a way of reasoning... anchored in a particular vocabulary that constitutes a particular version of the social world" [58], based in the assertion that "language constructs organizational reality, rather than simply reflects it” [59]. This emphasizes the analysis of verbal and written communication including organization stories [60, 61], rituals [62, 63], narratives [64], and metaphors [65] used by the organization and shared among members and used as a sense-making device [66]. Several recent studies offer detailed accounts of socio-ideological control in organizational contexts [67, 68, 69, 21].

One example of discourse constructing a certain organizational reality can be found in the concept of playbour (a play on the words play and labour) [70]. This occurs when organizations encourage participants to understand their unpaid contributions (such as unpaid video game modding) as 'fun' or a 'hobby', while the organization extracts value from their efforts. Their labor is paradoxically "voluntarily given and unwaged, enjoyed and exploited" [71]. This framing obscures other constructions of their participation-such as volunteering, work, or donating and suppresses the idea that they might be deserving of payment.

Despite the popularity of investigating socioideological control mechanisms in the organizational and managerial sciences, this is understudied in studies of crowd behavior. Yet, IS scholars have called for research to investigate the social processes operating in crowd-based projects [8]. Moreover, research demonstrating frequent communication among crowd workers [72] and the employment of community managers [51] suggests that crowdsourcing platforms may be more social and have greater organizational contact than sometimes believed.

3.4.1. Example of Socio-Ideological Control. The findings of a recent ethnography of the invite-only Yelp Elite Squad implicitly speaks to how socioideological control functions in a crowd-based platform [73]. The Yelp Elite Squad exists in cities around the world, members of which spend significant time visiting business, producing reviews, and participating in online forum discussions. In return, they are invited to free offline member-only events each month. They are incidentally coordinated by a community manager (CM), who is a trained and paid employee of Yelp. The study describes how discursive resources on the Yelp website and communication by the community manager foster a specific organizational reality. Elite Squad members are constructed as community members through discourse defining them as "the true heart of the Yelp community" and "a local authority and role model for the Yelp community" that has "got a lot of sway in the community" [74]. Coinciding with this, members reported that they strive to be Yelpy and Yelp-like, which includes behaviors like representing Yelp well to businesses, not demanding special treatment, recruiting new members, producing high quality reviews, and producing reviews often. Furthermore, the construction of their participation as community members was sufficiently powerful that when asked about their role in Yelp's business, members responded saying that they simply had not considered Yelp as a business or their labor as producing financial value. One member said that, "I just feel like, oh it's just a fun community and you know, get free dinners and it's just like friends are in it . . . I see Yelp as a community more than I do a business. Like, I never really thought of it being a business” [73].

Several implications arise from considering the Elite Squad from the perspective of socio-ideological control. First, the desire to be 'Yelpy' suggests that these individuals strongly identity with the organization and have internalized a set of values and 
beliefs that guide their behavior, which leads to them to self-monitor their actions even when they are not supervised (e.g., not demanding special treatment). How Yelp was able to achieve this becomes an interesting scholarly question. Second, these members internalized Yelp's version of organizational reality, in which their participation is understood through a civic-minded framing of 'community', rather than as a volunteer or as rational exchange with a for-profit business that financially benefits from their unpaid labor. The discursive resources that constitute the Elite Squad as a community obscure how their labor financially benefits Yelp-it was not until confronted with this idea by the interviewer that members were able to make sense of their participation differently. This suggests that hegemony-a process of gaining the active consent of a dominated group [75, 76] —and related considerations of asymmetrical power differences is a fruitful area of consideration for further research. Third, it highlights that some crowdbased platforms require individuals to operate in offline settings (e.g., visiting businesses to review) where they are not as easily survailled by the organization. Yet, the organization still has an interest in controlling the behavior of participants in these offline spaces. Here, disciplinary control, in which members self-monitor their behavior [55, 54, 23], emerges a powerful mechanism of organizational control. Fourth, it demonstrates that not all individuals in the crowd are subject to the same control mechanisms. Rather, there appears to be be less visible sub-groups [77] operating in the crowd subject to different mechanisms of organizational control. Overall, this study brings attention to the importance of considering discourse in the investigation of informal control strategies in crowdbased platforms.

\section{A Research Agenda for Crowd Behavior Based on Organizational Control Theory}

There is an assumption that crowd-based platforms imply the loss of control by organizations $[2,5]$. However, by clarifying mechanisms of organizational control and situating these within empirical studies of crowd-based platforms, this paper demonstrates that a diverse array of formal and informal organizational control mechanisms do indeed operate in this setting. Organizational control scholars note that researchers are often too singular in their conceptualizations and empirical focus when studying control mechanisms, frequently choosing to examine one type of control over others [10]. While the IS literature has revealed much about incentive systems [4] that target outputs, other types of formal and informal control mechanisms have been understudied. Yet these are critical aspects to investigate as scholars and designers seek to understand the best ways to govern the crowd.

To address this need, this paper encourages IS scholars to consider the various formal and informal control mechanisms operating at the input, behavior, and output targets of crowd-based platforms [10]. Through applying these concepts to studies of various crowd-based platforms, some key insights emerge.

While bureaucratic incentives systems that encourage certain outputs emerged as the most commonly studied type of control, far less examined are the rules and policies that act to constrain crowd behavior. Moreover, the study of self-policing at Yelp [36] suggests that some control mechanisms work in concert with each other (i.e., bureaucratic and socio-ideological) to encourage some users to flag content that deviates from what Yelp considers appropriate. Effectively, a control system was devised that encourages some users to flag and remove content that deviates from organizationally appropriate standards. This type of crowd behavior is both incredibly interesting and understudied. Future research may draw from concertive control literature [24] and studies that examine the interplay of several control mechanisms $[21,26]$ to further examine similar phenomena.

In regard to technological control, a study of the feedback system on a hospitality website revealed that the design and absence of some affordances acted to inhibit the contribution of negative reviews [48]. This suggests that a promising vein of crowd behavior research could more explicitly integrate the technological affordances and materiality literature $[44,46]$ in studies of organizational control. Similarly, the use of algorithms to automate control is likewise an emerging area of relevance to the functioning of crowd-based platforms [41, 42].

Emerging research on community managers suggests that some crowd-based platforms are using direct control of crowd members through local paid employees, who monitor and manage members of the crowd [73, 50, 51]. Further research is needed to clarity the role of these community managers and how the crowd responds to and resists being managed and managing each other. Still, this brings to focus the need to better understand how control systems evolve over time [10] on crowd-based platforms.

Informal control mechanisms emerged as important and understudied in crowd-based platforms. A study of the Elite Squad reveals strong commitment and identification to Yelp [73]. 
Moreover, how these members made sense of their organizational reality was shown to be influenced strongly by organizational discourse and discursive resources. Just as an incentive system can encourage certain behaviors through motivation, organizational discourse can encourage certain behaviors through constructing organizational realities and identities of crowd members. Future research could adopt discourse analysis [64, 57] to investigate how organizational language constructs certain meanings for participants and influences overall crowd behavior.

Finally, this review of the literature reveals that the power struggles inherent in organizational life that manifest in resistance, hegemony, and domination [29, 30, 14, 75] have largely been unexamined in the crowd behavior literature. Yet, examples presented in this paper illustrate the struggles emerge over defining what kind of content is appropriate [36, 35] or resisting the material impacts of crowdsourcing technologies [33]. Research adopting a critical perspective [14] to organizational control in crowd-based platforms could provide valuable insights into these issues.

Limitations are present in this review. While an effort was made to draw from literature investigating a variety of crowd-based platforms (e.g., Amazon, Reddit, etc.), research on Yelp is over-represented. This is because studies that explicitly or implicitly addressed issues relating to organizational control were scarce in other platforms. Rather, studies of these platforms would often examine large datasets of what is produced by the crowd (e.g., reviews.). Far fewer studies have investigated how this content is produced by the crowd (e.g., interviews, ethnography, etc.). The scarcity of these kinds of studies underscores the need for further research analyzing the important social and organizational processes influencing crowd behavior. Ultimately, this review leads to a range of interesting research questions:

- What is the full array of control mechanisms used in crowd-based platforms and how do they influence participation? How do control mechanisms enable and constrain the content produced by the crowd? How do various control mechanisms reinforce or contradict each other and how are these resolved? How do control mechanisms evolve over time and how does the crowd respond to changes?

- Who are the stakeholders in crowd-based platforms and what are their goals? What tensions arise from divergent stakeholder goals and how are they resolved? What is the 'right' kind of content produced by the crowd and who defines this? To what extent can control be resisted? How do control mechanisms produce winners and losers?

- What are the similarities and differences between control systems in traditional organizations and crowd-based platforms?

- What emergent or organizationally constructed socio-ideological norms guide crowd behavior? How are identities of crowd members socially constructed through organizational discourses?

In conclusion, many studies of crowd behavior focus on a limited range of incentive systems. Less frequent are investigations of the organizational and social aspects that influence how and what content is produced. This review presents the ontologically, theoretically, and methodological diverse literature of organizational control as a promising framework for investigating these aspects of crowd behavior. This review also encourages a more careful consideration of the term crowd and its popularization as an alternative to organizations. While crowd highlights many of the novel and different aspects of crowdbased platforms, it may also act to obscure from scholars the more traditional organizational structures that operate in crowd-based platforms. Scholars can build a more complete understanding of the complex sociotechnical processes influencing crowd behavior by remaining open to discovering unexpected control mechanisms operating in this context. While much can be learned about crowds by examining how they are different from organizations, there is also value in examining how they are similar.

\section{References}

[1] T. W. Malone, R. Laubacher and C. Dellarocas, "The Collective Intelligence Genome", IEEE Engineering Management Review 38(3), 2010, pp. 38-52.

[2] E. Bonabeau, "Decisions 2.0: The Power of Collective Intelligence", MIT Sloan Management Review 50(2), 2009, pp. 45-52.

[3] A. Kittur, J. V. Nickerson, M. Bernstein, E. Gerber, A. Shaw, J. Zimmerman, M. Lease and J. Horton, "The Future of Crowd Work", CSCW 2013 Proceedings, ACM, New York, NY, 2013, pp. 1301-1318.

[4] J. Pedersen, D. Kocsis, A. Tripathi, A. Tarrell, A. Weerakoon, N. Tahmasbi, J. Xiong, W. Deng, O. Oh and G.-J. De Vreede, "Conceptual Foundations of Crowdsourcing: A Review of Is Research", 46th Hawaii International Conference on System Sciences, IEEE, Wailea, Maui, HI, 2013, pp. 579-588.

[5] R. Jain, "Investigation of Governance Mechanisms for Crowdsourcing Initiatives", AMCIS 2010 Proceedings, Lima, Peru, 2010, pp. 557. 
[6] R. Buettner, "A Systematic Literature Review of Crowdsourcing Research from a Human Resource Management Perspective", 48th Hawaii International Conference on System Sciences, IEEE, 2015, pp. 46094618.

[7] Y. Zhao and Q. Zhu, "Evaluation on Crowdsourcing Research: Current Status and Future Direction", Information Systems Frontiers 16(3), 2014, pp. 417-434.

[8] P. Shachaf and H. Rosenbaum, "Online Social Reference: A Research Agenda through a STIN Framework", iConference '09, ACM, Chapel Hill, NC, 2009.

[9] W. G. Ouchi, "A Conceptual Framework for the Design of Organizational Control Mechanisms", Management Science 25(9), 1979, pp. 833-848.

[10] L. Cardinal, S. Sitkin and C. Long, "A Configurational Theory of Control", in S. Sitkin, L. Cardinal and K. Bijlsma-Frankema, eds., Organizational Control, Cambridge University Press, New York, NY, 2010.

[11] L. J. Kirsch, "The Management of Complex Tasks in Organizations: Controlling the Systems Development Process", Organization Science 7(1), 1996, pp. 1-21.

[12] M. L. Harris, R. W. Collins and A. R. Hevner, "Control of Flexible Software Development under Uncertainty", Information Systems Research 20(3), 2009, pp. 400-419.

[13] M. T. Rao, C. Brown and W. Perkins, "Host Country Resource Availability and Information System Control Mechanisms in Multinational Corporations: An Empirical Test of Resource Dependence Theory", Journal of Management Information Systems 23(4), 2007, pp. 11-28.

[14] R. Delbridge, S. Sitkin, L. Cardinal and K. BijlsmaFrankema, "Critical Perspectives on Organizational Control: Reflections and Prospects", in S. Sitkin, L. Cardinal and K. Bijlsma-Frankema, eds., Organizational Control, 2010, pp. 80-108.

[15] A. S. Tannenbaum, "Control in Organizations: Individual Adjustment and Organizational Performance", Administrative Science Quarterly, 1962, pp. 236-257.

[16] C. I. Barnard, The Functions of the Executive, Harvard University Press, 1968.

[17] M. Weber, Economy and Society: An Outline of Interpretive Sociology, Univ of California Press, 1978.

[18] E. H. Schein, "Organizational Culture", American Psychologist 45(2), 1990, pp. 109-119.

[19] H. Mintzberg, The Structuring of Organizations: A Synthesis of the Research, Prentice-Hall, Englewood Cliffs, NJ, 1979.

[20] M. Alvesson and H. Willmott, "Identity Regulation as Organizational Control: Producing the Appropriate Individual", Journal of Management Studies 39(5), 2002, pp. 619-644.

[21] M. Alvesson and D. Kärreman, "Interfaces of Control. Technocratic and Socio-Ideological Control in a Global Management Consultancy Firm", Accounting, Organizations and Society 29(3), 2004, pp. 423-444.

[22] S. R. Barley and G. Kunda, "Design and Devotion: Surges of Rational and Normative Ideologies of Control in Managerial Discourse", Administrative Science Quarterly, 1992, pp. 363-399.
[23] H. C. White, Identity and Control: A Structural Theory of Social Action, Princeton University Press, 1992.

[24] J. R. Barker, "Tightening the Iron Cage: Concertive Control in Self-Managing Teams", Administrative Science Quarterly, 1993, pp. 408-437.

[25] P. K. Tompkins and G. Cheney, "Communication and Unobtrusive Control in Contemporary Organizations", in R. D. McPhee and P. K. Tompkins, eds., Organizational Communication: Traditional Themes and New Directions, SAGE, Newbury Park, CA, 1985, pp. 179-210.

[26] D. Kärreman and M. Alvesson, "Cages in Tandem: Management Control, Social Identity, and Identification in a Knowledge-Intensive Firm", Organization 11(1), 2004, pp. 149-175.

[27] M. O’Toole and C. Grey, "'We Can Tell Them to Get Lost, but We Won't Do That': Cultural Control and Resistance in Voluntary Work", Organization Studies 37(1), 2016, pp. 55-75.

[28] T. Lawrence and S. Robinson, "Ain't Misbehavin: Workplace Deviance as Organizational Resistance", Journal of Management 33(3), 2007, pp. 378-394.

[29] S. R. Clegg, D. Courpasson and N. Phillips, Power and Organizations, SAGE, Thousand Oaks, CA, 2006.

[30] J. M. Jermier, D. E. Knights and W. R. Nord, eds., "Resistance and Power in Organizations", Routledge, London, UK, 1994.

[31] P. Fleming, "Metaphors of Resistance", Management Communication Quarterly 19(1), 2005, pp. 45-66.

[32] M. Parker, Against Management: Organization in the Age of Managerialism, Polity, Cambridge, UK, 2002.

[33] S. Hendrix, "Traffic-Weary Homeowners and Waze Are at War, Again. Guess Who's Winning?", The Washington Post, 2016.

[34] A. Weibel, "Managerial Objectives of Formal Control: High Motivation Control Mechanisms", in S. Sitkin, L. B. Cardinal and K. Bijlsma-Frankema, eds., Organizational Control, 2010, pp. 434-462.

[35] K. M. Kuehn, "'"There's Got to Be a Review Democracy": Communicative Capitalism, Neoliberal Citizenship and the Politics of Participation on the Consumer Evaluation Website Yelp.com", International Journal of Communication 7, 2013, pp. 19.

[36] K. M. Kuehn, "Brand Local: Consumer Evaluations as Commodity Activism on Yelp.com", Journal of Consumer Culture, 2015.

[37] B. Bozeman, Bureaucracy and Red Tape, Prentice Hall, Upper Saddle River, NJ, 2000.

[38] P. S. Adler and B. Borys, "Two Types of Bureaucracy: Enabling and Coercive", Administrative Science Quarterly 41(1), 1996, pp. 61-89.

[39] C. Perrow, Complex Organizations, Random House, New York, NY, 1986.

[40] L. Gossett, "Organization Control Theory", in S. Littlejohn and K. Foss, eds., Encyclopedia of Communication Theory, SAGE, Thousand Oaks, CA, 2009, pp. 706-710.

[41] J. Cheney-Lippold, "A New Algorithmic Identity Soft Biopolitics and the Modulation of Control", Theory, Culture \& Society 28(6), 2011, pp. 164-181.

[42] T. Gillespie, "The Relevance of Algorithms", in T. Gillespie, P. J. Boczkowski and K. A. Foot, eds., Media 
Technologies: Essays on Communication, Materiality, and Society, MIT Press, London, UK, 2014, pp. 167.

[43] M. Luca and G. Zervas, "Fake It Till You Make It: Reputation, Competition, and Yelp Review Fraud", Harvard Business School NOM Unit Working Paper No. 14-006, 2015.

[44] S. Faraj and B. Azad, "The Materiality of Technology: An Affordance Perspective", in P. M. Leonardi, B. Nardi and K. J., eds., Materiality and Organizing: Social Interaction in a Technological World, Oxford University Press, Oxford, UK, 2013, pp. 237-258.

[45] R. F. Zammuto, T. L. Griffith, A. Majchrzak, D. J. Dougherty and S. Faraj, "Information Technology and the Changing Fabric of Organization", Organization Science 18(5), 2007, pp. 749-762.

[46] V. Kaptelinin and B. Nardi, "Affordances in Hci: Toward a Mediated Action Perspective", Proceedings of the SIGCHI Conference on Human Factors in Computing Systems, ACM, 2012, pp. 967-976.

[47] A. Majchrzak and A. Malhotra, "Towards an Information Systems Perspective and Research Agenda on Crowdsourcing for Innovation", The Journal of Strategic Information Systems 22(4), 2013, pp. 257-268.

[48] D. A. Askay, "Silence in the Crowd: The Spiral of Silence Contributing to the Positive Bias of Opinions in an Online Review System", New Media \& Society 17(11), 2014, pp. 1811-1829.

[49] E. Schenk and C. Guittard, "Towards a Characterization of Crowdsourcing Practices", Journal of Innovation Economics \& Management (1), 2011, pp. 93107.

[50] A. Kerr and J. Kelleher, "The Recruitment of Passion and Community in the Service of Capital: Community Managers in the Digital Games Industry", Critical Studies in Media Communication 32(3), 2015, pp. 177-192.

[51] D. Ribeiro Soriano, F. J. Garrigos-Simon, R. Lapiedra Alcamí and T. Barberá Ribera, "Social Networks and Web 3.0: Their Impact on the Management and Marketing of Organizations", Management Decision 50(10), 2012, pp. 1880-1890.

[52] G. Kunda, Engineering Culture: Control and Commitment in a High-Tech Corporation, Temple University Press, Philadelphia, PA, 2006.

[53] K. A. Merchant, Control in Business Organization, Pitman Publishing, Marshfield, MA, 1985.

[54] M. Foucault, Discipline and Punish: The Birth of the Prison, Vintage, New York, NY, 1979.

[55] J. R. Barker and G. Cheney, "The Concept and the Practices of Discipline in Contemporary Organizational Life", Communications Monographs 61(1), 1994, pp. 1943.

[56] G. Morgan, Images of Organization, SAGE, Thousand Oaks, CA, 2006.

[57] N. Phillips and C. Oswick, "Organizational Discourse: Domains, Debates, and Directions", The Academy of Management Annals 6(1), 2012, pp. 435-481.

[58] S. Sveningsson and M. Alvesson, "Managing Managerial Identities: Organizational Fragmentation, Discourse and Identity Struggle", Human Relations 56(10), 2003, pp. 1163-1193.
[59] C. Hardy, T. B. Lawrence and D. Grant, "Discourse and Collaboration: The Role of Conversations and Collective Identity", Academy of Management Review 30(1), 2005, pp. 58-77.

[60] D. M. Boje, "The Storytelling Organization: A Study of Story Performance in an Office-Supply Firm", Administrative Science Quarterly, 1991, pp. 106-126.

[61] Y. Gabriel, Storytelling in Organizations: Facts, Fictions, and Fantasies, Oxford University Press, Oxford, UK, 2000.

[62] H. M. Trice and J. M. Beyer, "Studying Organizational Cultures through Rites and Ceremonials", Academy of management review 9(4), 1984, pp. 653-669.

[63] H. M. Trice and J. M. Beyer, The Cultures of Work Organizations, Prentice Hall, Englewood Cliffs, NJ, 1993.

[64] D. Grant, C. Hardy, C. Oswick and L. Putnam, eds., "The Sage Handbook of Organizational Discourse", SAGE, Thousand Oaks, CA, 2004.

[65] S. Koch and S. Deetz, "Metaphor Analysis of Social Reality in Organizations", Journal of Applied Communication Research 9(1), 1981, pp. 1-15.

[66] S. G. Harris, "Organizational Culture and Individual Sensemaking: A Schema-Based Perspective", Organization Science 5(3), 1994, pp. 309-321.

[67] M. Ezzamel and H. Willmott, "Strategy as Discourse in a Global Retailer: A Supplement to Rationalist and Interpretive Accounts", Organization Studies 29(2), 2008, pp. 191-217.

[68] H. M. Zoller, "Health on the Line: Identity and Disciplinary Control in Employee Occupational Health and Safety Discourse", Journal of Applied Communication Research 31(2), 2003, pp. 118-139.

[69] S. Mantere and E. Vaara, "On the Problem of Participation in Strategy: A Critical Discursive Perspective", Organization Science 19(2), 2008, pp. 341358.

[70] J. Kücklich, "Precarious Playbour: Modders and the Digital Games Industry", Fibreculture 5, 2005.

[71] T. Terranova, "Free Labor: Producing Culture for the Digital Economy", Social Text 18(2), 2000, pp. 33-58.

[72] M. L. Gray, S. Suri, S. S. Ali and D. Kulkarni, "The Crowd Is a Collaborative Network", CSCW 2016 Proceedings, 2016.

[73] D. A. Askay and L. Gossett, "Concealing Communities within the Crowd Hiding Organizational Identities and Brokering Member Identifications of the Yelp Elite Squad", Management Communication Quarterly 29(4), 2015, pp. 616-641.

[74] "Yelp Elite Squad", www.yelp.com/elite, Accessed 9/20/2015

[75] M. Humphreys and A. D. Brown, "Narratives of Organizational Identity and Identification: A Case Study of Hegemony and Resistance", Organization Studies 23(3), 2002, pp. 421-447.

[76] S. R. Clegg, Frameworks of Power, SAGE, Thousand Oaks, CA, 1989.

[77] C. R. Scott, Anonymous Agencies, Backstreet Businesses, and Covert Collectives: Rethinking Organizations in the 21st Century, Stanford University Press, Stanford, CA, 2013. 